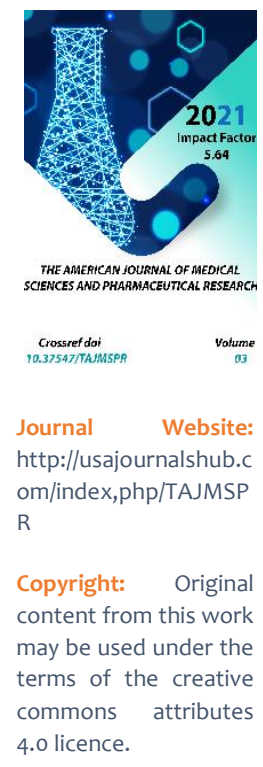

\section{Reconstructive Plastic Surgery For Auricular Defects}

\author{
Abdurashit Abdusalamovich Kayumkhodjayev \\ Doctor Of Medical Sciences (DSc), Head Of The Department Of Plastic And Reconstructive \\ Microsurgery, Republican Specialized Center Of Surgery Named Of Academician V. Vakhidov, \\ Uzbekistan
}

Jamshid Djurabayevich Rasulov

PhD, Surgeon Of The Department Of Plastic And Reconstructive Microsurgery, Republican Specialized Center Of Surgery Named Of Academician V. Vakhidov, Uzbekistan

Doniyorbek Makhamadsidikovich Ababakirov

Junior Researcher, Republican Specialized Center Of Surgery Named Of Academician V. Vakhidov, Uzbekistan

\title{
ABSTRACT
}

Objective - To improve the results of surgical treatment of various defects of the auricle by improving the methods of otoplasty.

Material and Methods - The study included patients with acquired traumatic defects and III degree inborn folded auricle. The work was carried out in the Department of Plastic and Reconstructive Microsurgery of the State Institution " RSSPMCS named after Academician V. Vakhidov" for the period from 1990 to 2020. In general, the comparative analysis of the results included 38 patients in the main group, among them in $13(34.2 \%)$ cases there were defects with extension to the central part of the auricle, 15 (39.5\%) patients with III degree deformity of the auricle (folded auricle), as well as in 9 cases - marginal defects of the auricle and in 1 case a patient with a total traumatic defect. The comparison group included 28 patients, 16 (57.1\%) - defects with extension to the central part of the auricle and 12 (42.9\%) patients with III degree deformity of the auricle. Accordingly, the effectiveness of the proposed otoplasty method for ear defects was assessed according to two categories of pathologies - defects with extension to the central part of the auricle and grade III ear deformity (folded auricle). The average age in the main group was $22.4 \pm 1.3$ years, in the comparison group $19.4 \pm 1.9$ years.

Results - Improved methods of reconstruction of an amputated but preserved auricle, with a peripheral defect of the auricle, with a folded auricle, and reconstructive otoplasty with defects with the capture of the central parts of the auricle are proposed. In total, complications developed in 8 (29.6\%) patients in the comparison group and 2 (7.1\%) in the main group. At the same time, the incidence of surgical complications, which subsequently led to the need for re-reconstruction, was $11.1 \%$ in the comparison group. There were no complications in the main group. In total, 6 (22.2\%) additional stages of otoplasty were performed in the comparison group. In the main group, an additional stage of surgery was required only in 1 (3.6\%) case of the formation of an unnatural skin fold. 
There was also a statistically significant difference in the number of additional plastic surgery stages performed for the complications noted above (criterion $\chi_{2}=4.305 ; \mathrm{df}=1 ; \mathrm{p}=0.039$ ). The average duration of surgery in the comparison group for all stages of reconstructive otoplasty was $220.7 \pm 2.7$ minutes, and in the main group after 2-stage otoplasty according to the proposed method - $189.5 \pm 1.9$ minutes (t-criterion $=-9,60 ; p<0.05)$.

Conclusion - The improved method of otoplasty in case of grade III defects or deformities of the auricle made it possible to reduce the overall incidence of complications from $29.6 \%$ to $7.1 \%$, and to reduce the need for repeated reconstructive interventions from $22.2 \%$ to $3.6 \%$, which, in general, led to a decrease in the period of complete rehabilitation from $4.4 \pm 0.1$ to $3.7 \pm 0.1$ months.

\section{KEYWORDS}

Inborn and acquired defects of the auricle, improvement of otoplasty methods, comparative analysis of the results.

\section{INTRODUCTION}

Defects and deformities of the auricle of inborn and acquired etiology are a common pathology of the maxillofacial region, and the number of patients with this problem is increasing every year [1-3]. In the population, deformities of the auricle are found in $20 \%$ of the population. The incidence of inborn malformations of the auricle is 3.5: 1000 newborns, and are distinguished by a variety of their variants. With the birth rate in the Republic of Uzbekistan 22.1 per 1000 population, up to 2400 children are born with anomalies in the development of the auricle per year. The multifactorial nature of isolated cases of the disease is assumed, however, to this day the etiological issue of anomalies in the development of the auricle remains unresolved, therefore, the number of children born with such defects does not decrease [4, 5].
In terms of the frequency of occurrence, acquired defects of the auricle are not inferior to congenital defects, and the treatment rate of patients for traumatic deformities and defects of the auricle is up to $42 \%$ of the total frequency of injuries of the maxillofacial region $[6,7]$. In most cases, damage to the auricle occurs as a result of domestic and industrial injuries. At the same time, regardless of the reasons that led to the loss of the outer ear, this defect is a serious aesthetic problem and, in addition to physical disability, affects the psychoemotional state of the patient, reduces the quality of life and can lead to social maladjustment, which is expressed in the limitation of social contacts, low self-esteem, anxiety and changes in personal attitudes and values. Surgical intervention in such cases is often the patient's last opportunity to return to a full life in society [8]. Today, there are many methods and original techniques for 
reconstructive otoplasty for congenital and acquired defects of the auricle, giving preference to one method or another, depending on the material for the auricle frame and the stages of the method $[9,10]$. At the same time, the increased requirements of patients for the aesthetic component of the treatment result, the operational complexity of the existing pathology, the lack of a single principle for choosing a method of surgical treatment for patients with ear defects, with a variety of individual original surgical techniques, as well as the need to develop new methods for effective treatment of ear defects, indicates the relevance of this study [11].

The aim of this study was to improve the results of surgical treatment of various defects of the auricle by improving the methods of otoplasty.

\section{MATERIAL AND METHODS}

The study included patients with acquired traumatic defects, with the exception of patients with post-burn cicatricial transformation, since in these cases, as a rule, not only the reconstruction of the auricle, but also the plastic of the surrounding tissues was required. The work was carried out in the Department of Plastic and Reconstructive Microsurgery of the State Institution " RSSPMCS named after Academician V. Vakhidov" for the period from 1990 to 2020. Also, our study included patients with such an inborn defect as a III degree folded auricle. In general, the comparative analysis of the results included 38 patients in the main group, among them in $13(34.2 \%)$ cases there were defects with extension to the central part of the auricle, 15 (39.5\%) patients with III degree deformity of the auricle (folded auricle), as well as in 9 cases - marginal defects of the auricle and in 1 case a patient with a total traumatic defect. The comparison group included 28 patients, 16 (57.1\%) - defects with extension to the central part of the auricle and 12 (42.9\%) patients with III degree deformity of the auricle. Accordingly, the effectiveness of the proposed otoplasty method for ear defects was assessed according to two categories of pathologies - defects with extension to the central part of the auricle and grade III ear deformity (folded auricle). The average age in the main group was $22.4 \pm 1.3$ years, in the comparison group $19.4 \pm 1.9$ years.

\section{Description of improved techniques for otoplasty for auricle defects.}

In traumatic amputation of the auricle, replantation using microvascular anastomoses is the best option for surgery. However, the complexity of such an intervention is associated with the small diameter of the anastomosed vessels and the possible injury of the entire auricular zone. In this connection, engraftment of a completely amputated auricle often ends in an unsatisfactory result.

Features of the reconstruction of an amputated but preserved auricle.

Operation stages:

Stage I - placement of the cartilaginous framework in a well-vascularized bed of the ear region (14 days after injury) (Fig. 1).

Stage II - lifting the previously implanted auricle with the skin. Plastic surgery behind the ear with a split skin graft (3 months after the first stage) (Fig. 2). 


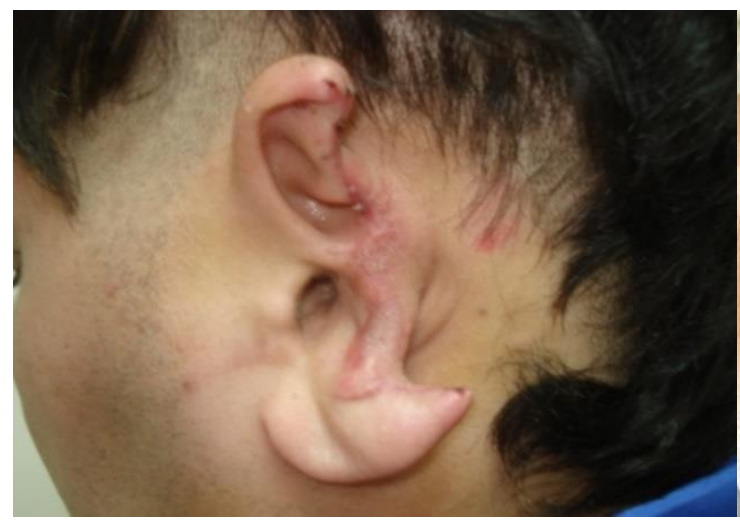

A

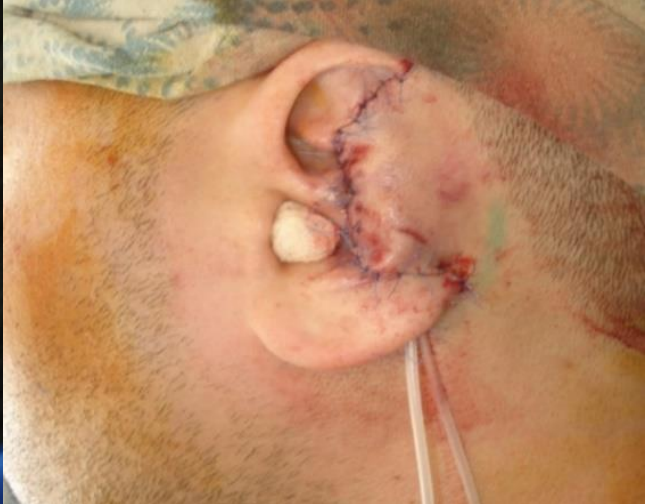

B

Figure: A. Auricle defect. B. Stage I of reconstruction - implantation of the cartilaginous framework into the behind-the-ear region with the installation of vacuum drains

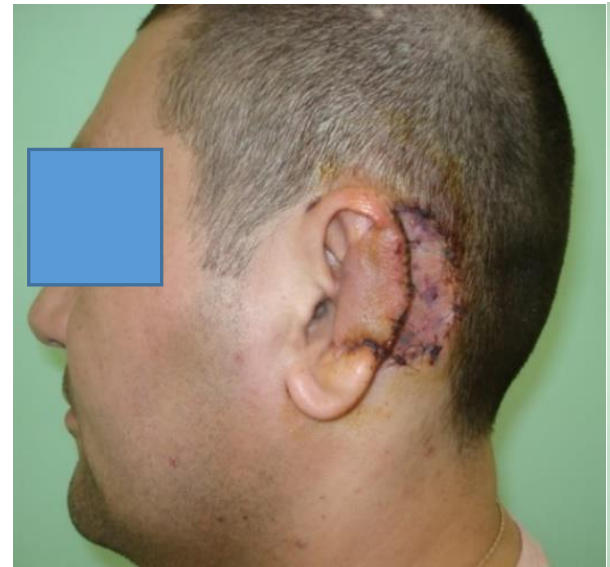

A

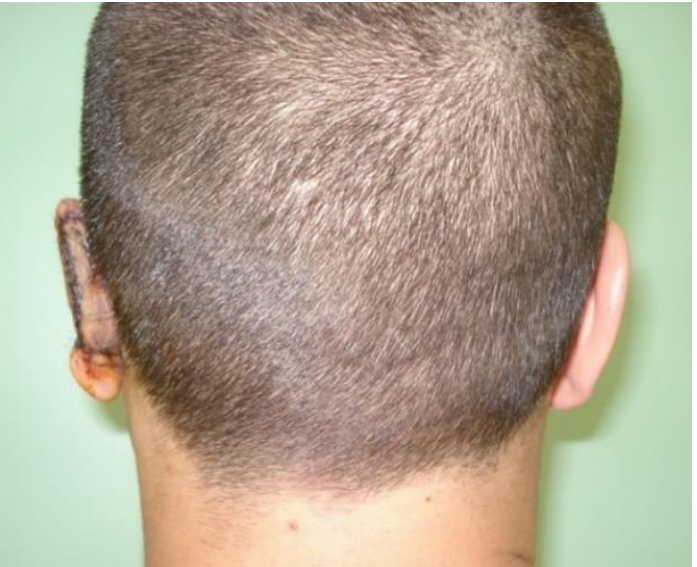

B

Figure: 2. The result of reconstructive otoplasty using the cartilaginous framework of the amputated auricle

The use of a waste material - a torn off auricle in plastic according to the proposed method in 2 stages allows avoiding the stage of taking an autocostal cartilage graft and making a skeleton of an auricle from it. In this case, the cartilaginous frame of the auricle amputated in case of trauma can be used. Thus, with amputation of the auricle (class 3), it becomes possible to use the waste material as a finished frame. Reconstruction is performed in two stages and there is no need to use an allograft or autocostal cartilage framework.

Features of otoplasty for a peripheral defect of the auricle with a curl defect are characterized by the performance of a two-stage operation using a behind-the-ear fascial skin flap (FSF). The operation is performed under local infiltration anesthesia. At the first stage, FSF is formed on the feeding stem. After excision of 
the scar tissue, the distal part of the flap is

sutured into the defect (Fig. 3)

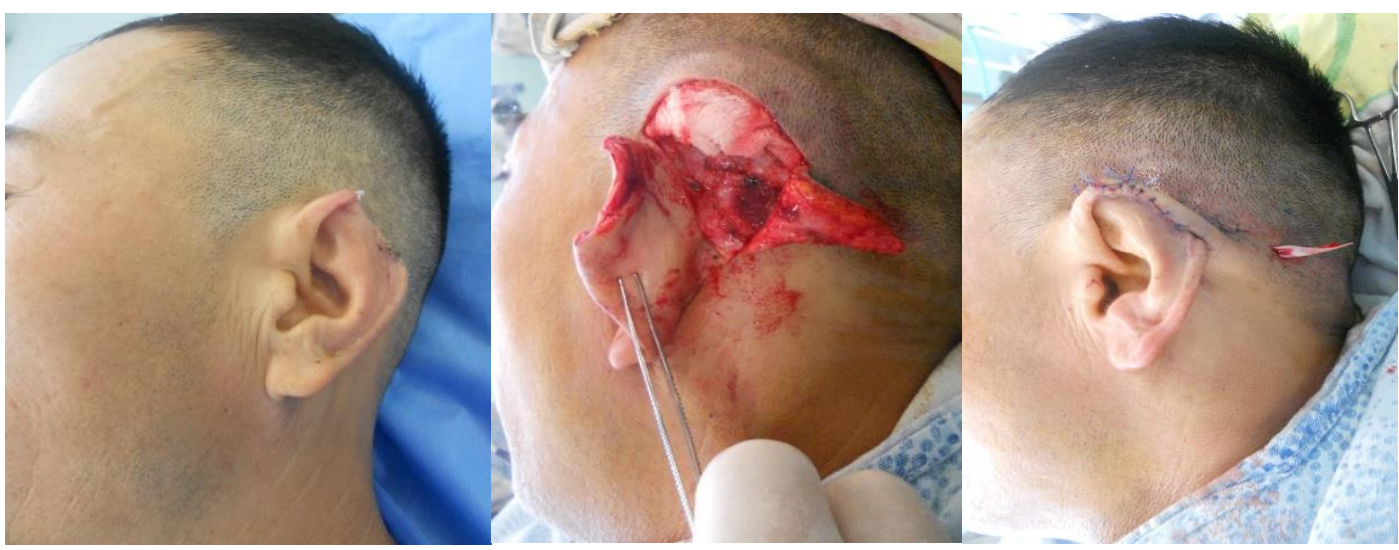

Figure: 3. Patient M., 28 years old. Marginal defect of the auricle. $1^{\text {st }}$ stage of plastics. Flap formation behind the ear. Replacement of the proximal part of the defect

Three weeks later, the second stage is performed: cutting off the leg of the flap, final plasty of the auricle defect and suturing of the donor area (Fig. 4.5).

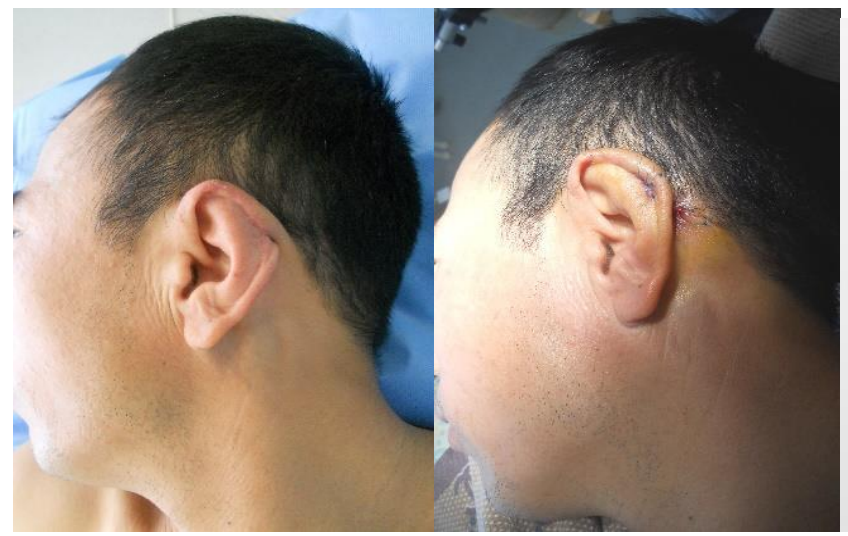

A
B

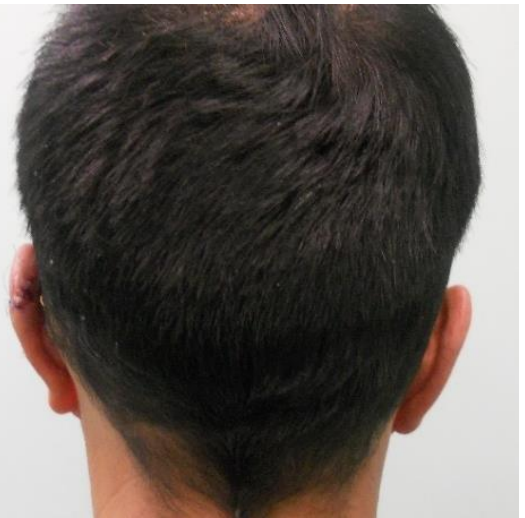

C

Figure: 4. The same patient. A - after the first stage of plastics. B, C - final plastic surgery of the auricle defect

For a marginal defect in the middle and lower part of the auricle curl, a behind-the-ear flap on the distal pedicle was used (Figs. 5 and 6 ). 


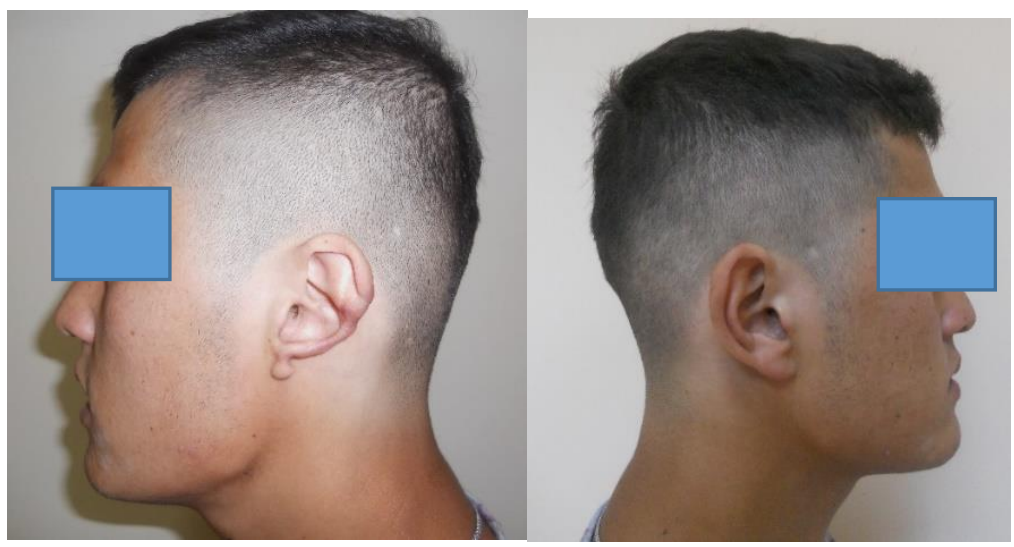

A

B

Figure: 5. Patient B., 22, A - marginal defect of the auricle; B - healthy right auricle

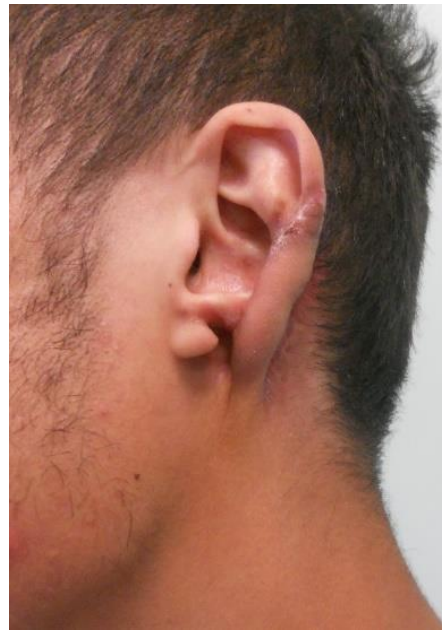

A

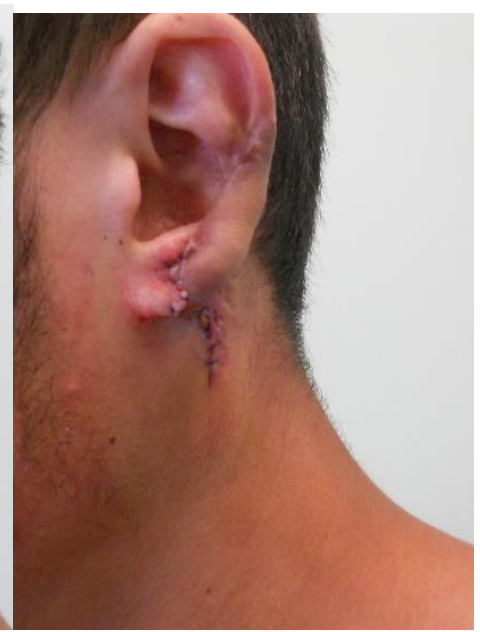

B

Figure: 6 . The same patient. A - condition after stage I of plastics; B - final plasty of the auricle defect with suturing of the donor area

Thus, the most acceptable method of plastic surgery for marginal (peripheral) defects of the auricle is the use of a pediatric fascial flap behind the ear. In all cases (9 patients), good aesthetic results were obtained.
Improvement of the method of reconstructive otoplasty with a folded auricle.

One of the most difficult inborn deformities of the auricle for reconstruction is the folded auricle (grade III deformity). To improve the 
functional and aesthetic results of otoplasty with this defect of the auricle, an improved method of reconstructive otoplasty has been proposed. The method includes restoration of the missing part of the auricle from the framework of the autologous cartilage implanted in the behind-the-ear region. In particular, at the first stage, the missing part of the auricle is formed from the autocostal cartilage and, after being sewn into the defect, is implanted into the behind-the-ear region. Three months later, the second stage is performed, which includes lifting the previously implanted framework together with the skin and performing the final plastic surgery.

The proposed method is carried out as follows. The operation is performed under intravenous anesthesia in combination with local infiltration anesthesia, in two stages. In contrast to the prototype method, at the first stage, a frame made of autocostal cartilage, prepared according to the size of the defect, was used with sculptural revision of the missing parts of the auricle (Fig. 7 and 8). The upper part of the ear cartilage is fixed in the correct position to the temporal fascia. After fixing the cartilaginous frame in the defect of the auricle, it is immersed in the subcutaneous pocket of the ear region (Fig. 9 and 10). Two thin drainage tubes are placed under the frame and behind it, connected to a vacuum system, which is removed on the fifth day after the operation.

The next stage of the operation is performed three months after the first operation as the microcirculation recovers and the edema subsides. At the same time, the implanted part of the auricle is separated from the tissues of the head and the space behind the ear is formed. The implantation of a spacer from the remnant cartilage is also performed to create a normal protrusion angle of the auricle. The defect in the posterior surface of the ear frame is closed with a split skin graft (Fig. 11).

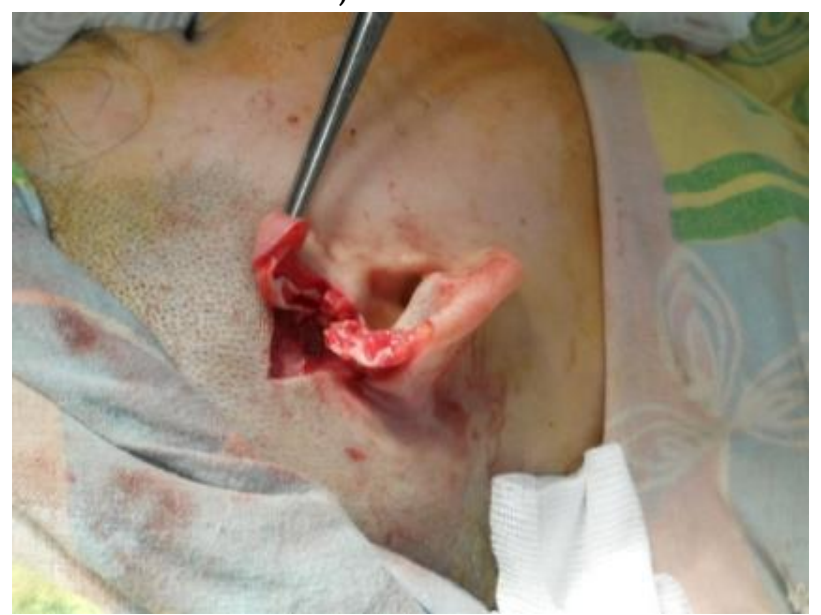

Figure: 7. Folded auricle III degree. Dissection of the auricle, moving the upper part up and forward to the intended point 


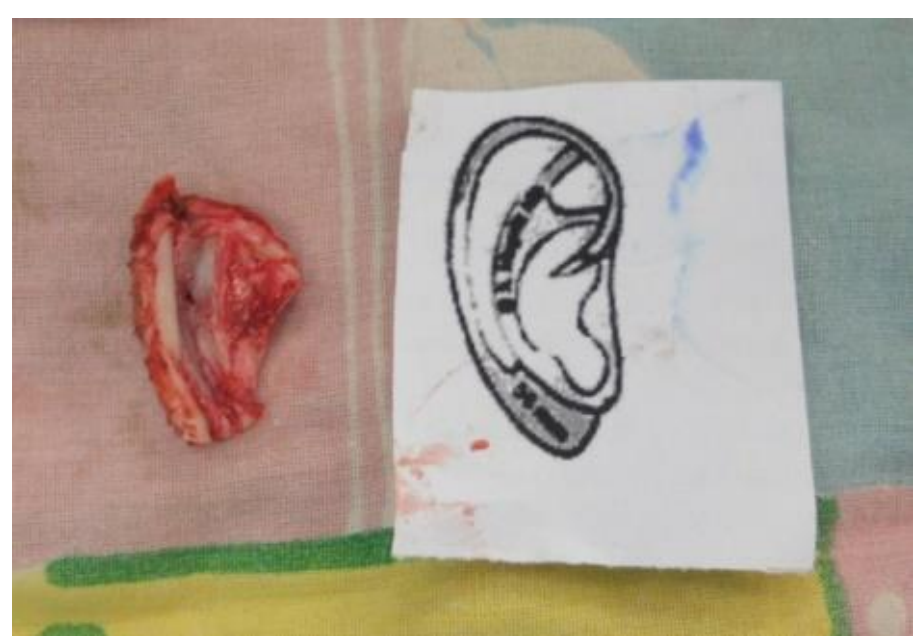

Figure: 8 . A prepared part of the auricle frame from autocostal cartilage based on a template

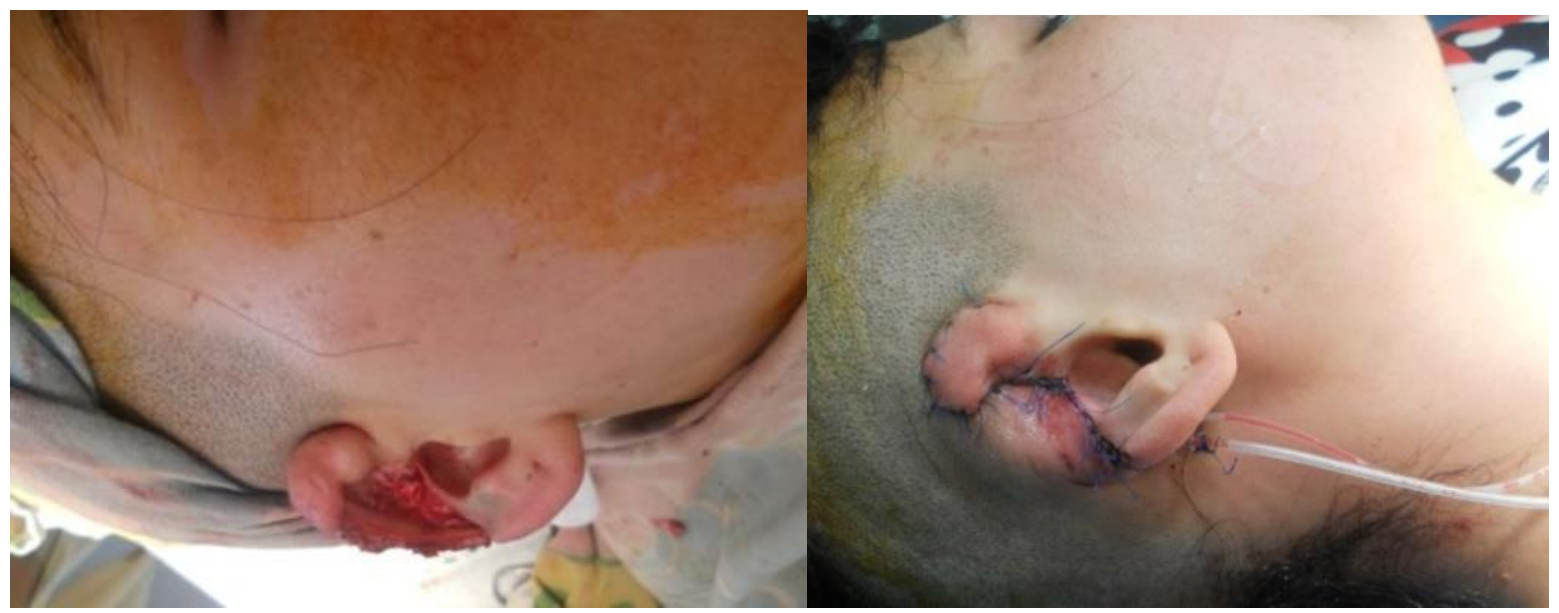

Figure: 9. Cartilaginous framework fixed in Figure: 10. Implanted framework in the the defect of the auricle behind-the-ear region and vacuum drainage 


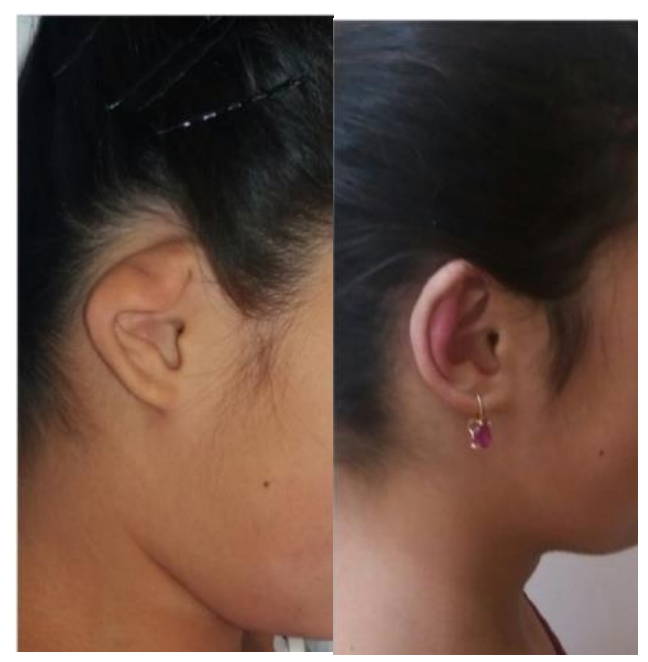

Figure: 11. View of the patient before surgery and in the long-term period after reconstruction

Thus, the choice of the method of surgery with a folded auricle should be based on a clear definition of the anatomical defect and on the measurement of differences in the size of the altered and normal ear. Due to the parameters of the defect with a folded auricle of the III degree, reconstruction requires the use of a cartilaginous frame. Accordingly, the use of a frame defect prepared in size from autocostal cartilage with sculptural refinement makes it possible to obtain clear aesthetically acceptable contours of the missing parts of the auricle. In turn, the use of a cartilaginous support makes it possible to obtain a normal "protrusion" angle of the reconstructed auricle. The improved method was used in the reconstruction of a III degree folded auricle in 15 cases.

Reconstructive otoplasty for defects involving the central parts of the auricle. If the defect of the auricle captures not only the curl, but also the central parts, then reconstructive otoplasty can also be carried out using a frame made of autocostal cartilage according to the proposed method. In these cases, the operation is performed in two stages. At the first stage, the autocostal cartilage is harvested and the missing part of the auricle is fabricated according to the template taken from the healthy auricle. The fabricated frame is implanted in the behind-the-ear region (Fig. 1215). 


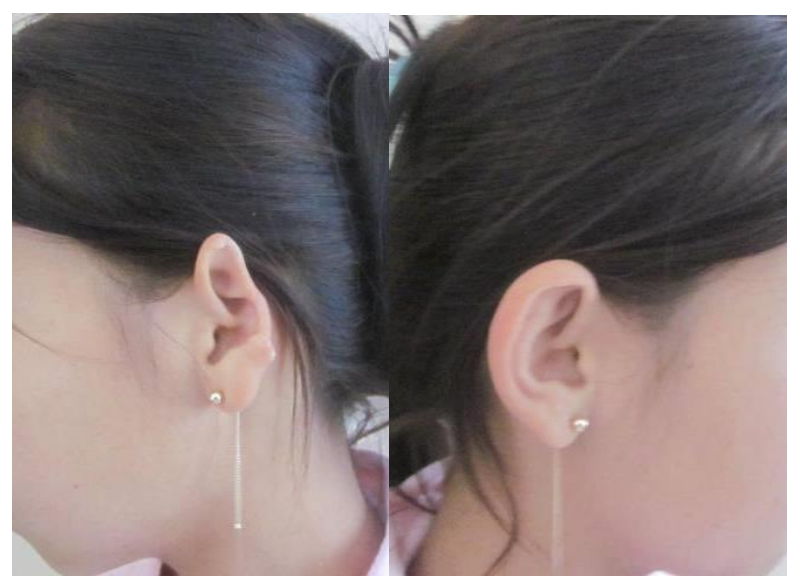

A

B

Figure: 12. Patient G., 16 years old. A - central defect of the auricle; B - healthy auricle

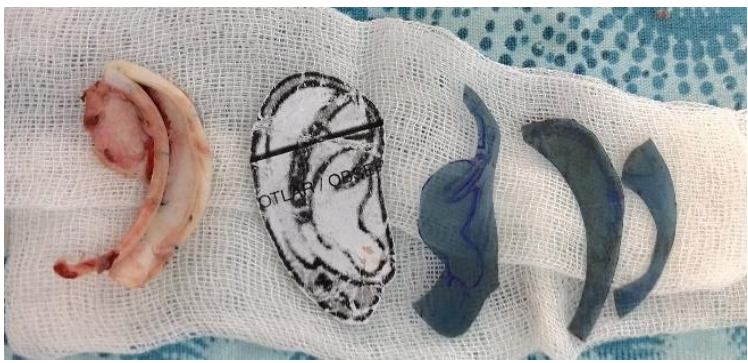

Figure: 13. Making the missing part according to the template taken from a healthy auricle 


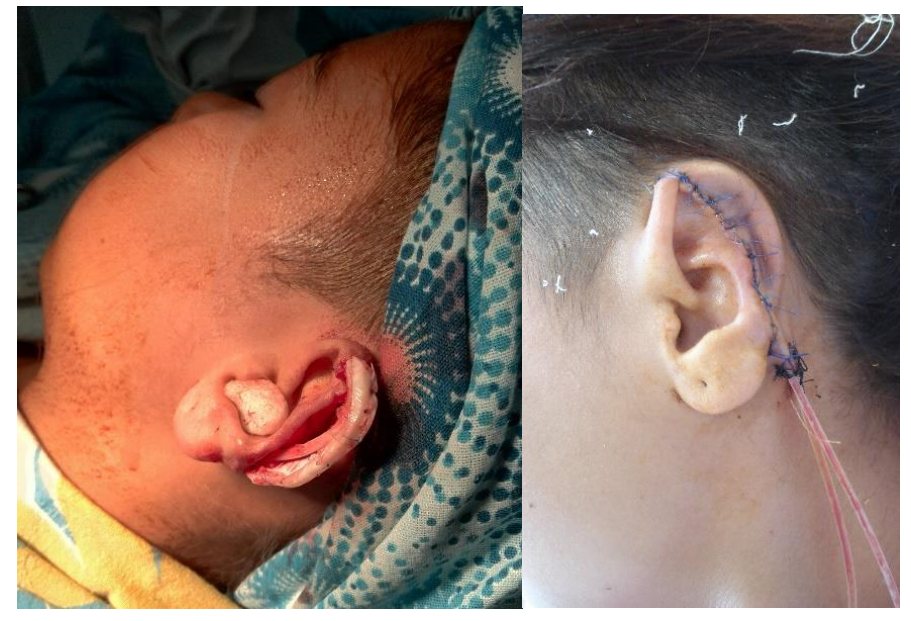

A

B

Figure: 14. A. Stage I: implantation of the framework in the behind-the-ear region;

B. Raising a previously implanted framework with final repair

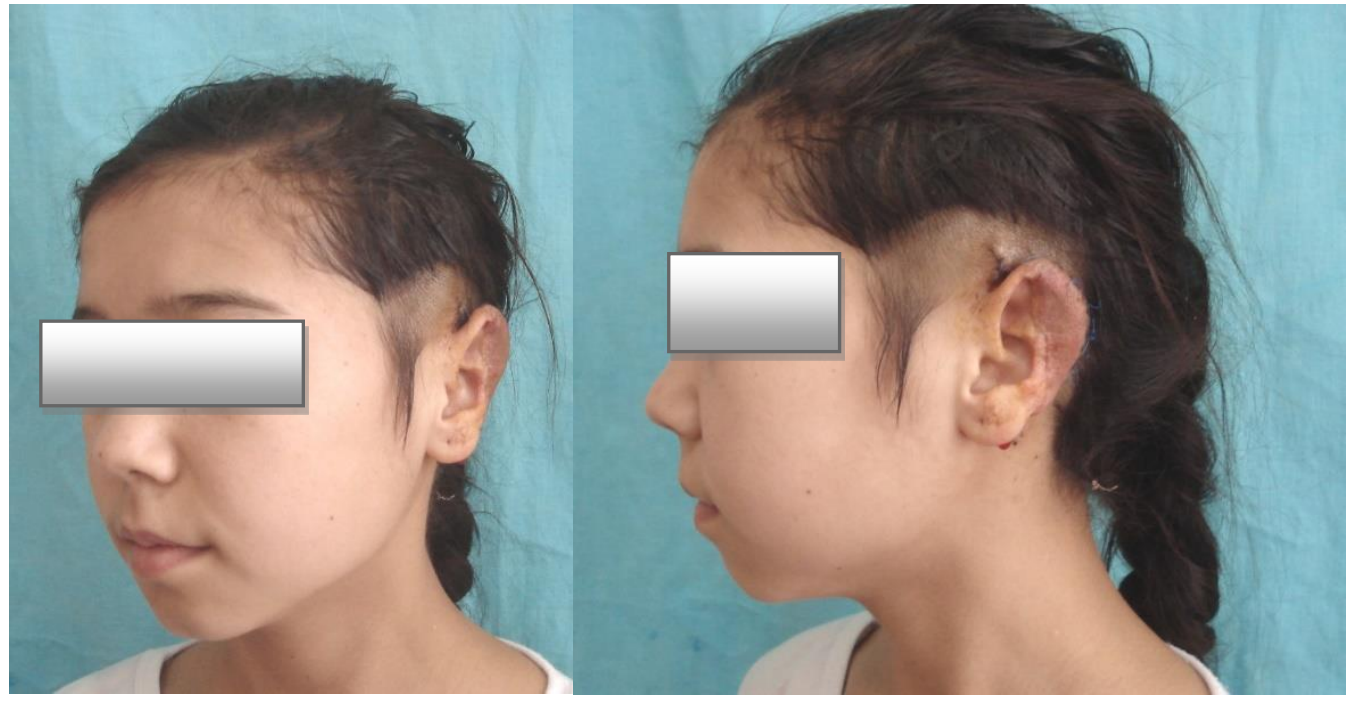

Figure: 15. The same patient. After the second stage of reconstructive otoplasty

At the second stage, after 3 months, the previously implanted framework is lifted with the final plasty. According to the improved method of plastic surgery in two stages using a cartilaginous framework was performed in 13 cases. 


\section{RESULTS}

In total, complications developed in 8 (29.6\%) patients in the comparison group and $2(7.1 \%)$ in the main group (Table 1).

Table 1. Frequency of postoperative complications in the group with auricular defects

\begin{tabular}{|c|c|c|c|c|}
\hline \multirow[t]{2}{*}{ Complication } & \multicolumn{2}{|c|}{$\begin{array}{l}\text { Comparison group } \\
(n=27)\end{array}$} & \multicolumn{2}{|c|}{$\begin{array}{l}\text { Main group } \\
\quad(n=28)\end{array}$} \\
\hline & abs. & $\%$ & abs. & $\%$ \\
\hline \multicolumn{5}{|c|}{ After $1^{\text {st }}$ stage of the operation with implantation of the frame } \\
\hline $\begin{array}{l}\text { Marginal necrosis of the skin over the graft with } \\
\text { exposure of part of the framework }\end{array}$ & 2 & $7,4 \%$ & 0 & $0,0 \%$ \\
\hline Cartilage lysis & 1 & $3,7 \%$ & 0 & $0,0 \%$ \\
\hline Total patients with complications & 3 & $11,1 \%$ & 0 & $0,0 \%$ \\
\hline $\mathrm{X} 2$ criterion & \multicolumn{4}{|c|}{3,$291 ; d f=1 ; p=0,070$} \\
\hline \multicolumn{5}{|c|}{ After reconstructive stages } \\
\hline Violation of the contour of the curl and antihelix & 3 & $11,1 \%$ & 1 & $3,6 \%$ \\
\hline $\begin{array}{l}\text { Violation of the normal protrusion of the } \\
\text { formed SD }\end{array}$ & 3 & $11,1 \%$ & 1 & $3,6 \%$ \\
\hline Retraction of the formed curl & 1 & $3,7 \%$ & & $0,0 \%$ \\
\hline Formation of an unnatural fold of skin & 2 & $7,4 \%$ & 1 & $3,6 \%$ \\
\hline Recurrence of severe deformity & 1 & $3,7 \%$ & & $0,0 \%$ \\
\hline Total patients with complications & 8 & $29,6 \%$ & 2 & $7,1 \%$ \\
\hline $\mathrm{X} 2$ criterion & \multicolumn{4}{|c|}{4,$672 ; d f=1 ; p=0,031$} \\
\hline
\end{tabular}

Note: the group includes only patients with traumatic defects with damage to the central part of the auricle and a folded auricle of the III degree

At the same time, the incidence of surgical complications, which subsequently led to the need for repeated reconstruction, was $11.1 \%$ in the comparison group (in 2 cases, marginal skin necrosis over the graft with exposure of a part of the skeleton and in 1 case, lysis of the cartilage). There were no such complications in the main group. Also, among other complications noted in 8 patients in the comparison group and in 2 in the main group, it is possible to distinguish a violation of the contour of the curl and antihelix, violation of the normal protrusion of the formed auricle, retraction of the formed curl and the formation of an unnatural skin fold. In a comparative aspect, there was a statistically significant difference in the incidence of postoperative complications, both after stage 1 of the 
operation with frame implantation $\left(\chi^{2}=3.291\right.$; $\mathrm{df}=1 ; \mathrm{p}=0.070)$ and after the final stages of reconstruction $\left(\chi^{2}=4.672 ; \mathrm{df}=1 ; \mathrm{p}=0.031\right)$.

In total, 6 (22.2\%) additional stages of otoplasty were performed in the comparison group: 2 (7.4\%) in cases of violation of the normal protrusion of the formed auricle, $2(7.4 \%)$ in cases of the formation of an unnatural skin fold, $1(3,7 \%)$ in case of violation of the contour of the curl and antihelix and 1 more (3.7\%) - in the case of recurrence of pronounced deformity of the auricle (Table 2), in the main group an additional stage of surgery was required only in $1(3.6 \%)$ case the formation of an unnatural fold of skin. There was also a statistically significant difference in the number of additional plastic surgery stages performed for the complications noted above (criterion $\chi_{2}=4.305 ; \mathrm{df}=1 ; \mathrm{p}=0.039$ ).

Table 2. Number of additional reconstructive stages performed

\begin{tabular}{|l|c|c|c|c|}
\hline \multirow{2}{*}{\multicolumn{1}{|c|}{ Complication }} & \multicolumn{2}{c|}{$\begin{array}{c}\text { Comparison group } \\
(\mathrm{n}=27)\end{array}$} & \multicolumn{2}{c|}{$\begin{array}{c}\text { Main group } \\
(\mathrm{n}=28)\end{array}$} \\
\cline { 2 - 5 } & abs. & $\%$ & abs. & $\%$ \\
\hline Violation of the contour of the curl and antihelix & 1 & $3,7 \%$ & 0 & $0,0 \%$ \\
\hline $\begin{array}{l}\text { Violation of the normal protrusion of the formed } \\
\text { SD }\end{array}$ & 2 & $7,4 \%$ & 0 & $0,0 \%$ \\
\hline Formation of an unnatural fold of skin & 2 & $7,4 \%$ & 1 & $3,6 \%$ \\
\hline Recurrence of severe deformity & 1 & $3,7 \%$ & 0 & $0,0 \%$ \\
\hline Total & 6 & $22,2 \%$ & 1 & $3,6 \%$ \\
\hline X2 criterion & & 4,$305 ; \mathrm{df}=1 ; \mathrm{p}=0,039$ \\
\hline
\end{tabular}

The average duration of the operation (Table 3 ) in the comparison group for all stages of reconstructive otoplasty was $220.7 \pm 2.7$ minutes, and in the main group after 2-stage otoplasty according to the proposed method $189.5 \pm 1.9$ minutes $(t$-criterion $=-9.60 ; p$
$<0.05)$. Obtaining such results, as can be seen from the table. 4.3 , contributed to a significant reduction in the duration of surgery at stage 1 : from $123.5 \pm 10.1$ minutes in the comparison group to $94.5 \pm 1.6$ minutes in the main group of patients (t-test $=-11.70 ; p<0,05)$. 
Table 3. Duration of surgery for all stages of reconstructive otoplasty (minutes)

\begin{tabular}{|l|c|c|c|c|c|c|c|c|}
\hline \multirow{3}{*}{ Stages } & \multicolumn{3}{|c|}{ Comparison group $(\mathrm{n}=27)$} & \multicolumn{3}{c|}{ Main group } & \multirow{2}{*}{ t-test } & \multirow{2}{*}{$\mathrm{P}$} \\
\cline { 2 - 9 } & $\mathrm{M}$ & $\delta$ & $\mathrm{m}$ & $\mathrm{M}$ & $\delta$ & $\mathrm{m}$ & & \\
\hline 1 stage & 123,5 & 10,1 & 1,9 & 94,5 & 8,2 & 1,6 & $-11,70$ & $<0,05$ \\
\hline 2 stage & 97,2 & 7,9 & 1,5 & 95,0 & 7,7 & 1,5 & $-1,06$ & $>0,05$ \\
\hline Total & 220,7 & 13,8 & 2,7 & 189,5 & 10,0 & 1,9 & $-9,60$ & $<0,05$ \\
\hline
\end{tabular}

As for the time periods between the stages of surgical treatment (Table 4), it can be noted that in the comparison group the second stage was carried out on average after $4.4 \pm 0.1$ months, while in the main group this period was $3.7 \pm 0.1$ months ( $t$-test $=-4.42 ; p>0.05$ ).

Table 4. Time periods between stages of reconstructive otoplasty (months)

\begin{tabular}{|c|c|c|c|c|c|c|c|c|}
\hline \multirow{2}{*}{ Stages } & \multicolumn{6}{|c|}{ Comparison group $(\mathrm{n}=\mathbf{2 7})$} & \multicolumn{4}{|c|}{ Main group $(\mathrm{n}=28)$} & \multirow{2}{*}{ t-test } & \multirow{2}{*}{$\mathrm{p}$} \\
\cline { 2 - 7 } & $\mathrm{M}$ & $\delta$ & $\mathrm{m}$ & $\mathrm{M}$ & $\delta$ & $\mathrm{m}$ & & \\
\hline 1 - 2 stage & 4,4 & 0,7 & 0,1 & 3,7 & 0,5 & 0,1 & $-4,42$ & $<0,05$ \\
\hline
\end{tabular}

The duration of the hospital period (Table 5) in aggregate for all stages of reconstructive otoplasty in the comparison group was $10.1 \pm$
0.2 days, which was significantly longer than in the main group, where this indicator was $9.0 \pm$ 0.2 days ( $t$-test $=-3.86 ; \mathrm{p}<0.05$ ).

Table 5. Length of hospital stay for all stages of reconstructive otoplasty (days)

\begin{tabular}{|l|c|c|c|c|c|c|c|c|}
\hline \multirow{2}{*}{ Stages } & \multicolumn{6}{|c|}{ Comparison group $(\mathrm{n}=12)$} & \multicolumn{3}{c|}{ Main group $(\mathrm{n}=29)$} & \multirow{2}{*}{ t-test } & \multirow{2}{*}{$\mathrm{p}$} \\
\cline { 2 - 8 } & $\mathrm{M}$ & $\delta$ & $\mathrm{m}$ & $\mathrm{M}$ & $\delta$ & $\mathrm{m}$ & & \\
\hline 1 stage & 4,6 & 0,7 & 0,1 & 4,5 & 0,7 & 0,1 & $-0,70$ & $>0,05$ \\
\hline 2 stage & 5,5 & 0,8 & 0,1 & 4,5 & 0,7 & 0,1 & $-4,87$ & $<0,05$ \\
\hline Total & 10,1 & 1,1 & 0,2 & 9,0 & 1,0 & 0,2 & $-3,86$ & $<0,05$ \\
\hline
\end{tabular}

The summary data on the duration of all stages of reconstructive otoplasty for defects or deformities of the auricle of the III degree are shown in Fig. 16. Thus, it can be concluded that the proposed method of otoplasty in case of defects or deformities of the III degree UR makes it possible to reduce the average number of otoplasty stages (including additional) from 2.2 in the comparison group to 2.0 in the main group $(t=2.10 ; p<0.05)$, the duration of the operation at all stages - from 3.7 hours to 3.2 hours ( $t=9.60 ; p<0.05)$, the duration of the hospital period at all stages from 10.1 to 9.0 days $(t=3.86 ; p<0.05)$ and the time periods between the stages - from 4.4 to 3.7 months $(t=4.42 ; p<0.05)$. 


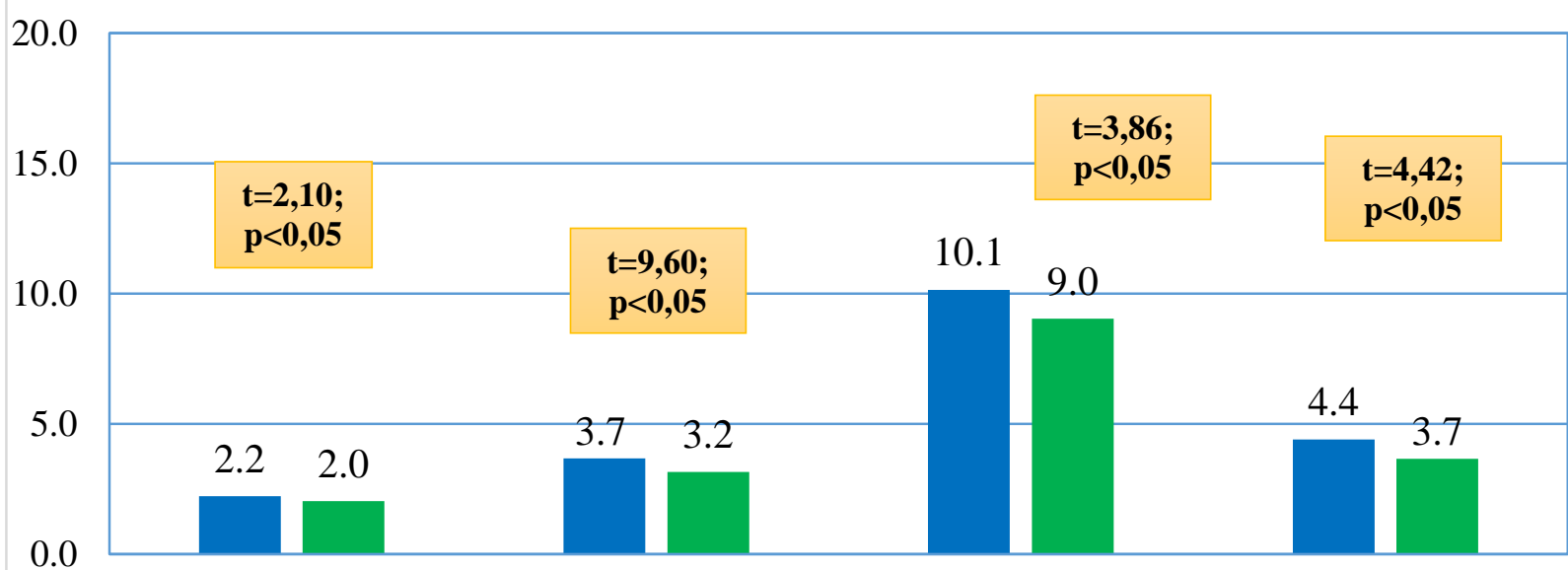

Average number of Duration of surgery for Length of hospital stay Time periods between otoplasty stages all stages (hours) for all stages (days) stages (months) (including additional)

- Comparison group $(\mathrm{n}=27) \quad \square$ Main group $(\mathrm{n}=28)$

Figure: 16. Summary data on the duration of all stages of reconstructive otoplasty for microtia

\section{CONCLUSION}

In case of auricle amputation (class 3), it is possible to use waste material as a finished frame. Reconstruction is performed in two stages and there is no need to use an allograft or autocostal cartilage framework.

The most acceptable method of plastic surgery for marginal (peripheral) defects of the auricle is the use of a skin-fascial flap behind the ear on the leg. In all cases (9 patients), good aesthetic results were obtained.

The choice of the method of surgery with a folded auricle should be based on a clear definition of the anatomical defect and on the measurement of differences in the size of the altered and normal ear. Due to the parameters of the defect with a folded auricle of the III degree, reconstruction requires the use of a cartilaginous frame.

The use of a frame made of autocostal cartilage with sculptural refinement, prepared according to the size of the defect, allows obtaining clear aesthetically acceptable contours of the missing parts of the auricle. In turn, the use of a cartilaginous support makes it possible to obtain a normal "protrusion" angle of the reconstructed auricle.

An improved method of otoplasty for grade III auricle defects or deformities made it possible to reduce the overall complication rate from $29.6 \%$ to $7.1 \%$ ( $\left.x^{2}=4.672 ; d f=1 ; p=0.031\right)$, and to reduce the need for repeated reconstructive interventions from $22,2 \%$ to $3.6 \%\left(x^{2}=4.305 ; \mathrm{df}\right.$ 
$=1 ; p=0.039)$, which in general caused $a$ decrease in the period of complete rehabilitation from $4.4 \pm 0.1$ to $3.7 \pm 0.1$ months $(\mathrm{p}<0,05)$.

\section{REFERENCES}

1. Ebrahimi A, Kazemi A, Rasouli $H R$, Kazemi M, Kalantar Motamedi MH. Reconstructive Surgery of Auricular Defects: An Overview. Trauma Mon. 2015;20(4):e28202.

doi:10.5812/traumamon.28202.

2. Watson D, Hecht A. Repair of Auricular Defects. Facial Plast Surg Clin North Am. 2017;25(3):393-408.

3. Ghassemi A, Modabber A, Talebzadeh $M$, et al. Surgical management of auricular defect depending on the size, location, and tissue involved. J Oral Maxillofac Surg. 2013;71:232-242.

4. Cubitt JJ, Chang LY, Liang D, Vandervord J, Marucci DD. Auricular reconstruction. J Paediatr Child Health. 2019 May;55(5):512-517.

5. Jovic TH, Stewart K, Kon M, Whitaker IS. "Auricular reconstruction: A sociocultural, surgical and scientific perspective". J Plast Reconstr Aesthet Surg. 2020;73(8):1424-1433.

6. Stewart K, Majdak-Paredes E. Injury patterns and reconstruction in acquired ear deformities. Facial Plast Surg. 2015;31:645-656.

7. Kolodzynski $M N$, Kon $M$, Egger $S$, Breugem CC. Mechanisms of ear trauma and reconstructive techniques in 105 consecutive patients. Eur Arch Otorhinolaryngol. 2017;274(2):723-728.

8. Li D, Xu F, Zhang R, Zhang Q, Xu Z, Li Y, Wang C, Li T. Surgical Reconstruction of Traumatic Partial Ear Defects Based on a Novel Classification of Defect Sizes and Surrounding Skin Conditions. Plast Reconstr Surg. 2016;138(2):307-316.

9. Habiba NU, Khan AH, Khurram MF, Khan MK. Treatment options for partial auricle reconstruction: a prospective study of outcomes and patient satisfaction. J Wound Care. 2018;27(9):564-572.

10. Selcuk CT, Durgun M, Bozkurt M, Kinis $\mathrm{V}$, Ozbay M, Bakir S. The reconstruction of full-thickness ear defects including the helix using the superior pedicle postauricular chondrocutaneous flap. Ann Plast Surg. 2014;72(2):159-63.

11. Helal HA, Mahmoud NA, Abd-Al-Aziz AA. Reconstruction of post-traumatic full-thickness defects of the upper onethird of the auricle. Plast Surg (Oakv). 2014;22(1):22-5. 